\title{
Performance evaluation of various cooling-lubrication techniques in grinding of hardened AISI 4340 steel with vitrified bonded CBN wheel
}

\author{
Ricardo Fernando Damasceno ${ }^{1}$ - Rodrigo de Souza Ruzzi ${ }^{1}$ - Thiago Valle França ${ }^{1}$.

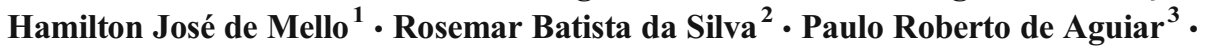 \\ Eduardo Carlos Bianchi ${ }^{1}$
}

Received: 23 November 2016 / Accepted: 18 April 2017 /Published online: 4 May 2017

(C) Springer-Verlag London 2017

\begin{abstract}
In the grinding process, to achieve improved tribological conditions between wheel-chip-workpiece interfaces and minimize the effects of thermal damages, such as loss of hardness and cracks for example, it is needed to minimize the high amount of heat generated by the process. In addition to the correct adjusting of the cutting parameters, it is also to select an efficient coolant delivery technique (that includes coolant concentration, coolant flow rate, and nozzle geometry) and properties of abrasive wheels for successful grinding. Therefore, seeking for cooling-lubrication techniques with improved coolant efficiency and that can preserve surface integrity of the workpiece, as well as that make rational use of cutting fluids, becomes indispensable. Into this context, this investigation aims to evaluate the performance of different coolant-lubrication conditions during the surface grinding of AISI 4340 steel with a vitrified bonded CBN superabrasive wheel under various cutting conditions. Three coolant delivery techniques (flooding, MQL, and optimized Webster system) were tested. The input cutting parameters was depth of cut values $(20,50$, and $80 \mu \mathrm{m})$. Tangential component force, specific energy, surface roughness, microhardness and surface
\end{abstract}

residual stress of the machined surfaces, as well as abrasive wheel wear and $\mathrm{G}$ ratio were monitored and used to assess the performance of the different coolant-lubrication under the conditions investigated. The results showed that, in general, the optimized technique outperformed other coolant techniques in all the parameters evaluated because of the better access of cutting jet to the grinding area, especially at more severe cutting conditions. MQL technique exhibited superior performance in terms of cutting force and specific energy, but it was in general responsible for generation of poorer finishing and the highest microhardness variation in regions closer to machined surfaces. With regard the residual stresses, they were predominantly compressive, irrespective of the depth of cut and cooling-lubrication technique employed. A slight variation of the residual stresses values with depth of cut after machining with the optimized and the MQL coolant technique, unlike the pattern observed after machining with the conventional coolant delivery technique. Finally, no significant thermal damages or cracks were observed on the machined surfaces after machining under all the cutting conditions.

Rosemar Batista da Silva

rosemar.silva@ufu.br

Eduardo Carlos Bianchi

bianchi@feb.unesp.br

Ricardo Fernando Damasceno

ricardo_damasceno@ig.com.br

Rodrigo de Souza Ruzzi

roruzzi@hotmail.com

Thiago Valle França

thiagovf@feb.unesp.br

Hamilton José de Mello

hamilton@feb.unesp.br
1 Department of Mechanical Engineering, UNESP, Av. Eng. Luiz E. C. Coube, 14-01, CEP, Bauru, SP 17033-360, Brazil

2 School of Mechanical Engineering, Federal University of Uberlandia, Av. João Naves de Ávila, 2121, CEP: 38408-100, Uberlandia, MG, Brazil

3 Department of Electrical Engineering, UNESP, Av. Eng. Luiz E. C. Coube, 14-01, CEP, Bauru, SP 17033-360, Brazil 
Keywords Grinding · Cutting fluid · AISI 4340 steel · CBN wheel $\cdot$ Surface integrity

\section{Introduction}

In grinding, chips are generated by the action of several cutting edges distributed and oriented randomly along the wheel structure when in contact with workpiece. Energy is consumed to form the chip by plastically deforming the workpiece or to overcome friction because of the mechanical and chemical actions of wheel abrasives being plunging and sliding against the workpiece [1]. During the chip formation stages (friction, elastic/plastic deformation, and shearing), most of the generated energy is converted into heat, raising the temperature within the cutting zone. If this temperature is not maintained within acceptable levels, thermal stress occurs in the workpiece and may compromise the ground surface integrity by cracking, warping, developing high residual stress, and dimensional inaccuracy [2].

Cutting fluids are delivered to the grinding zone to reduce heat generation, especially of the workpiece. This function is achieved by reducing friction due to surface lubrication. Moreover, it reduces straining and cutting power because part of the heat is removed from that zone (cooling) [3]. Furthermore, fluids are responsible for removing excess of formed chips, maintaining the cutting tool (grinding wheel) clean, and decreasing corrosion of the involved materials [4].

When properly applied, cutting fluids can increase productivity and reduce costs by enhancing cutting speed, feed-rate, and depth of cut. Actually, this application may also increase tool life, reduce the surface roughness, enhance dimensional accuracy, and further reduce the required power [5].

However, the cutting fluids are hazardous to the environment. Its disposal is considerably expensive and involves laborious procedures. The costs associated with cutting fluids (i.e., filtering and discard) may be greater than the costs related to the cutting tool. In addition, some cutting fluid substances can cause health issues on machine operators, such as severe dermatitis caused by prolonged exposure [6]. So, their negative effects to human and the environment have made industries to pay careful attention with regard to its proper selection. In addition to meet tribological requirements, the cutting fluid must comply with environmental protection standards dictated by international criteria and certifications such as ISO 14,000 . Therefore, companies are looking at alternatives to reduce their consumption, or even stop its usage in production processes. Environmental considerations and human health have been placed as a priority [7].

A first interesting alternative is the minimum quantity of lubricant technique (MQL), also referred to as a nearly dry process (near dry grinding-NDG). Compared to dry grinding condition, MQL technique has substantially increased grinding workpiece quality [7]. This technique is considered to be between conventional lubrication/cooling and dry machining and many benefits from its application in the metal working industry, especially in grinding operations, have been reported in the literature. MQL technique combines the functionality of the cooling/lubrication with an extremely low consumption of oil $(20-250 \mathrm{ml} / \mathrm{h})$ that are delivered to the wheelworkpiece contact interface. The small amount of fluid may be sufficient to reduce cutting friction, thereby minimizing the heat generated by maintaining the tool within a temperature range that does not impair its performance [8].

Effectiveness of a grinding fluid is dependent on several factors such as workpiece material, abrasive wheel, operational severity, delivery method, coolant properties, frequency of dumping, cleaning, and recharging, filtration method [9] as well as quality of water and working environment (related to external contamination such as atmospheric air, hydraulic oil leaks, and other impurities). Particularly with regard to delivery method, there are some aspects often neglected and that play an important role in grinding efficiency such as nozzle geometry [4], number of nozzles and their positioning [10], coolant pressure delivery, and flow rate. For instance, enough coolant should be capable to enter the grinding area without splashing, or, in some cases, poor infiltration of fluid into the cutting region hinders heat removal. Fluid jet coherency also must be considered in grinding efficiency. Ebbrell [4] reported that fluid jet can be deflected from the contact zone during cutting due to the air layer formed by grinding wheel movement at high speeds. These authors have recommended the use of air-deflectors in front of the nozzle to ensure jet coherence, thereby the proper access of cutting fluid in the grinding zone.

Therefore, the study of these aspects must be taken into consideration to achieve an optimized lubri-cooling system. Into this context, another interesting alternative to conventional cooling technique is to optimize fluid application. Improper selection and delivery of cutting fluid to the grinding zone can lead to surface burning, generation of tensile stress and cracks, among other problems. These factors adversely affect the performance and process quality and thus eliminate the main functions of fluid (lubrication, cooling, and cleaning). Fluid delivery optimization would increase lubricity and cooling properties of the process, promoting better chip removal, and smaller dispersions within the cutting zone. In addition, a correct selection of nozzle design and its positioning is needed [11].

Workpiece quality is dependent on the coolant delivery method when performing grinding. A jet focused directly on the cutting zone is significantly able to reduce the temperature. Nonetheless, it is necessary for high-speed jets to penetrate the cutting zone effectively. Thus, the nozzle should be designed to cause the least possible turbulence during the fluid output [12]. 
Silva [13] evaluated the performance of the MQL technique during an external cylindrical plunge grinding of AISI 4340 quenched and tempered steel with aluminum oxide $\left(\mathrm{Al}_{2} \mathrm{O}_{3}\right)$ and $\mathrm{CBN}$ wheels compared to conventional coolant method. The authors reported a slightly decrease in roughness values $\left(R_{\mathrm{a}}\right)$ and diametrical grinding wheel wear after machining the MQL method. This technique also gave lower tangential cutting force and specific energy compared to the conventional coolant method what authors attributed to excellent lubricity of the MQL oil.

The effects of compressed cold air application were analyzed by Choi [14] during cylindrical grinding of a spindle shaft material (SCM21) white alumina wheel (WA) and a CBN wheel. The authors explored the cooling effects of compressed air and compared them with regular lubricants and reported that compressed cold air was effective in diminishing thermal defects of the workpiece, thereby being a solution for environmental pollution. They also found lower surface roughness values after machining in the presence of compressed cold airflow and they decreased with increase in the air jet speed.

Hafenbraedl and Malkin [15] have evaluated the performance of the MQL technique employed in internal cylindrical grinding in comparison to the conventional cooling technique (soluble oil delivered at 5\% concentration and at a flow rate of $5.3 \mathrm{l} / \mathrm{min}$ ) and observed that the improved lubrication of the MQL technique was responsible for the lowest cutting force, specific energy conventional, and wheel wear rate. However, these authors reported that surface roughness values $\left(R_{\mathrm{a}}\right)$ were slightly higher after machining with MQL technique. Klocke [16] also reported that MQL technique was not as effective as conventional coolant method in terms of surface quality of machined workpiece, and they attributed its poor performance mainly to the difficulty of MQL to remove heat removal from grinding zone.

Although the number of studies on optimizing cutting fluid delivery has grown steadily, currently the literature is still scarce. Thus, further studies are needed to enable cutting fluid use by industries more rationally.

This paper mainly aimed to evaluate the performance of the different coolant-lubrication conditions during the tangential surface grinding of AISI 4340 steel with a vitrified bonded CBN superabrasive wheel under various cutting conditions. This paper also envisages to give a contribution to industrial and academic machining users that are seeking for cleaner manufacturing processes. Depth of cut values and coolant delivery techniques (flooding and MQL) as well as nozzle geometries were used as input variables. Two geometries of nozzles were tested: the first is the one that accompanies the machine while the second is based on that proposed by Webster [12], termed in this investigation as optimized deliver method. Tangential cutting force, specific energy, surface roughness, abrasive wheel wear, $\mathrm{G}$ ratio, microhardness, and surface residual stress of the machined surfaces were monitored and used to assess the performance of the different coolant-lubrication conditions investigated.

\section{Experimental procedures}

The material used in the experiments was AISI 4340 quenched and tempered steel $(0.4 \% \mathrm{C}, 1.8 \% \mathrm{Ni}, 0.8 \% \mathrm{Cr}$, $0.23 \% \mathrm{Mo}, 0.68 \% \mathrm{Mn}, 0.23 \% \mathrm{Si}), 62 \mathrm{HRc}$ with $100 \mathrm{~mm} \times 200 \mathrm{~mm} \times 10 \mathrm{~mm}$ in size. Applications of this material are in manufacturing of several types of gears, shafts, and other parts such as spindles, couplings, and pins in which are required higher tensile/yield strength in relatively large sections.

The experimental trials were carried out in a SULMECÂNICA 1055E peripheral surface grinding machine with a vitrified bonded CBN super abrasive wheel having the following dimensions $350 \mathrm{~mm} \times 20 \mathrm{~mm} \times 5 \mathrm{~mm}$ and with designation-SNB151Q12VR2, 25\% vol-—medium grain size (B151) and open. In order to remove any imperfections from the wheel surface caused by previous grinding operation, and not influence the output variables, the dressing operation remained constant for all runs, using a conglomerate-type dresser by 10 passes with depth of dressing (ad) of $0.02 \mathrm{~mm}$ and dressing speed (vd) of $7.4 \mathrm{~mm} / \mathrm{s}$. The main factor to be investigated is variation of the equivalent chip thickness that, according to Marinescu [17], is directly proportional to the depth of cut and workspeed, and inversely proportional to the cutting speed. Since the grinding machine used to perform the tests has a higher precision in the control of the depth of cut, this parameter was varied, while the other parameters were kept constant to avoid their influence on the results. Details of the experimental conditions employed in this investigation are shown in Table 1.

Each trial was performed until $16,000 \mathrm{~mm}^{3}$ of removed material, so there were performed 400,160, and 100 cycles for depth of cut of $0.02,0.05$, and $0.08 \mathrm{~mm}$, respectively; only one stroke was performed for each cycle. Cutting speed and workspeed were kept constant in all the trials. With respect of workspeed, it is important to remark that its value was adopted after performing several preliminary machining trials in which it generated the lowest machine-tool vibration emission, therefore ensure satisfactory stability to the system.

Table 1 Summary of the cutting conditions for the experimental trials when grinding the AISI4340 steel with CBN superabrasive wheel

\begin{tabular}{ll} 
Wheel rotation $\left(n_{\mathrm{s}}\right)(\mathrm{rpm})$ & 1800 \\
Wheel speed $\left(V_{\mathrm{s}}\right)(\mathrm{m} / \mathrm{s})$ & 33 \\
Workspeed $\left(V_{\mathrm{w}}\right)(\mathrm{m} / \mathrm{s})$ & 0.033 \\
Radial depth of cut $(\mathrm{mm})$ & $0.02,0.05$, and 0.08 \\
\hline
\end{tabular}


The equipment employed for the MQL technique was a the Accu-Lube 79053D, supplied by the ITW Chemical Products Ltd., which has a pulsating oil supply system and allows the compressed air and lubricant flows to be adjusted separately. Details of the MQL system device with the main operating parts listed were presented by Silva [13].

An especially designed nozzle with $150 \mathrm{~mm}$ length (Fig. 1) was developed for the MQL technique at Laboratory of Abrasion Machining of the São Paulo State UniversityUNESP, Faculty of Engineering of Bauru, Sao Paulo. The nozzle design allows, through the flow rate control, compressed-air speed to be very close to the wheel speed, $V_{\mathrm{s}}$ of $33 \mathrm{~m} / \mathrm{s}$. This velocity allows the compressed air and lubricant mixture to reach the tool and workpiece contact zone, improving cooling and lubrication. A pressure gauge and a regulator were used to reach the desired speed. MQL system consists of an air compressor, pressure regulator, a dispenser, and a spray nozzle.

A straight vegetable oil (SVO), Accu-Lube LB-1000 with chlorinated extreme pressure additives - supplied by ITW Chemical Products Ltd. - was used in the MQL technique. It is a non-toxic and biodegradable with flash point of $279^{\circ} \mathrm{C}$, which is recommended for machining of ferrous and nonferrous materials. It was delivered in the grinding area at a flow rate of $100 \mathrm{ml} / \mathrm{h}(0.1 \mathrm{l} / \mathrm{h})$. The distance from nozzle to the grinding area was set at $40 \mathrm{~mm}$. The setup to the application of the MQL technique is shown in Fig. 2a.

For the conventional delivery coolant technique, it was used the original machine nozzle that supplies fluid at a flow rate of $27.5 \mathrm{l} / \mathrm{min}(1650 \mathrm{l} / \mathrm{h})$ and pressure of $0.40 \mathrm{MPa}$, which was controlled by using pressure and flow meters coupled in the piping between the pump and the nozzle. The setup to the application of the conventional technique is shown in Fig. 2 b. For the optimized technique, the same flow rate was applied, but under different pressure (0.7 MPa), so that the fluid flow could have the same wheel peripheral velocity $(33 \mathrm{~m} / \mathrm{s})$. The setup to the application of the optimized technique is shown in Fig. 2c. The cutting fluid employed when performing the trials with conventional and optimized coolant technique was the water-soluble synthetic oil (ULTRACUT 370 supplied by ROCOL) at a concentration of $5 \%$.

Details of the experimental cooling-lubrication conditions employed in this investigation are shown in Table 2.

Tangential cutting force and specific energy were monitored through an electronic module that acquires the voltage and current values (from the spindle motor) and transform them into a voltage signal compatible to be sent to an acquisition board and further handled by data acquisition system based on LabVIEW 7.1® software, National Instruments®. From the input signal, the software evaluated the electric power and through the motor characteristics was possible to obtain the mechanical power. Thus, from the mechanical power and the grinding wheel rotation and diameter was calculated the tangential cutting force.

A specific material volume of $5000 \mathrm{~mm}^{3} / \mathrm{mm}$ was stipulated as stopping criterion for the machining trials.

At the end of each test, the average of the surface roughness values, $R_{\mathrm{a}}$, was measured at three different equidistant regions of the machined surface, transversal to cutting direction, with aid of a Taylor Hobson Surtronic $3+$ texture-measuring instrument with cut-off length set at $0.8 \mathrm{~mm}$.

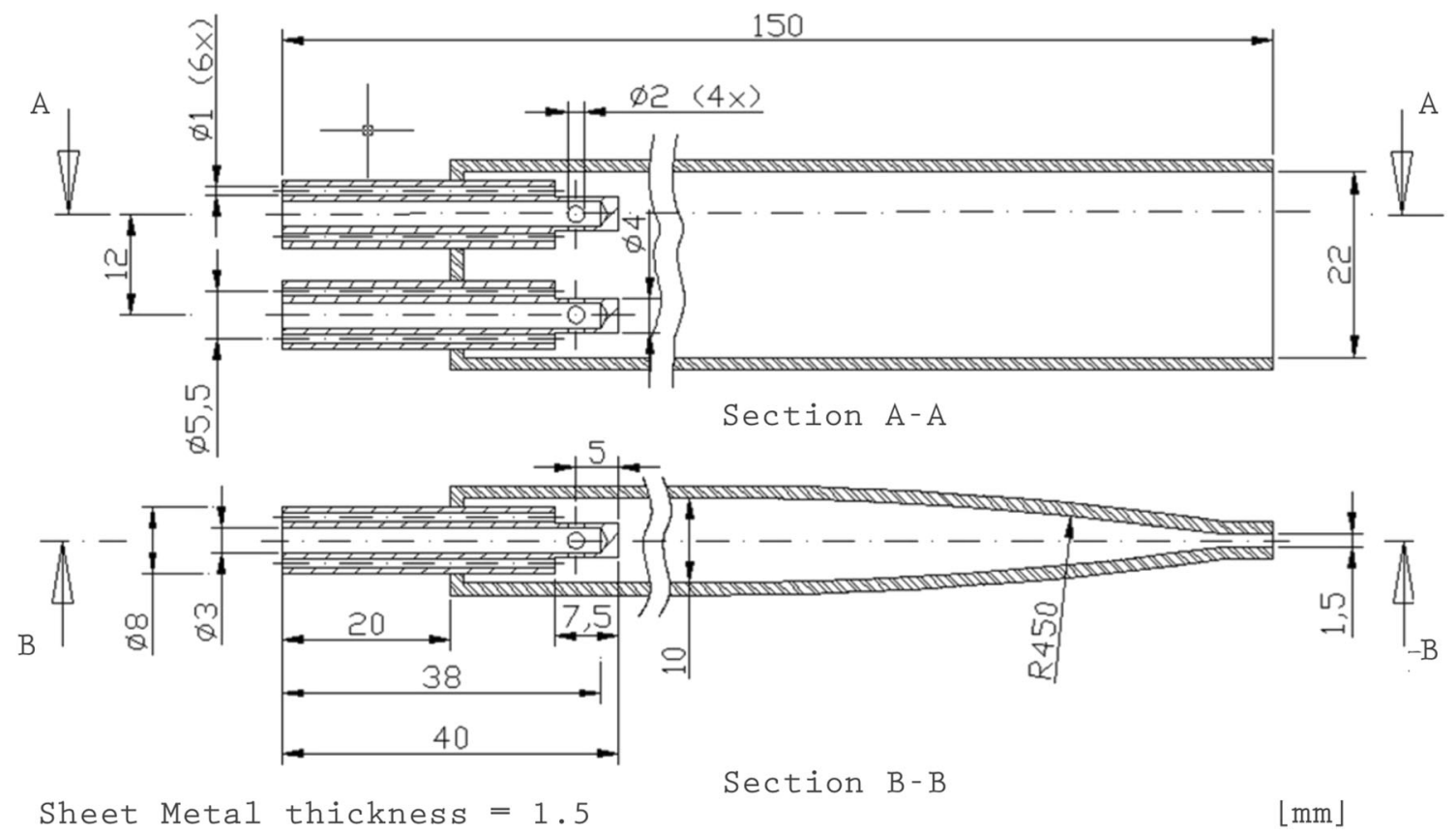

Fig. 1 Nozzle design used for the MQL technique [18] 

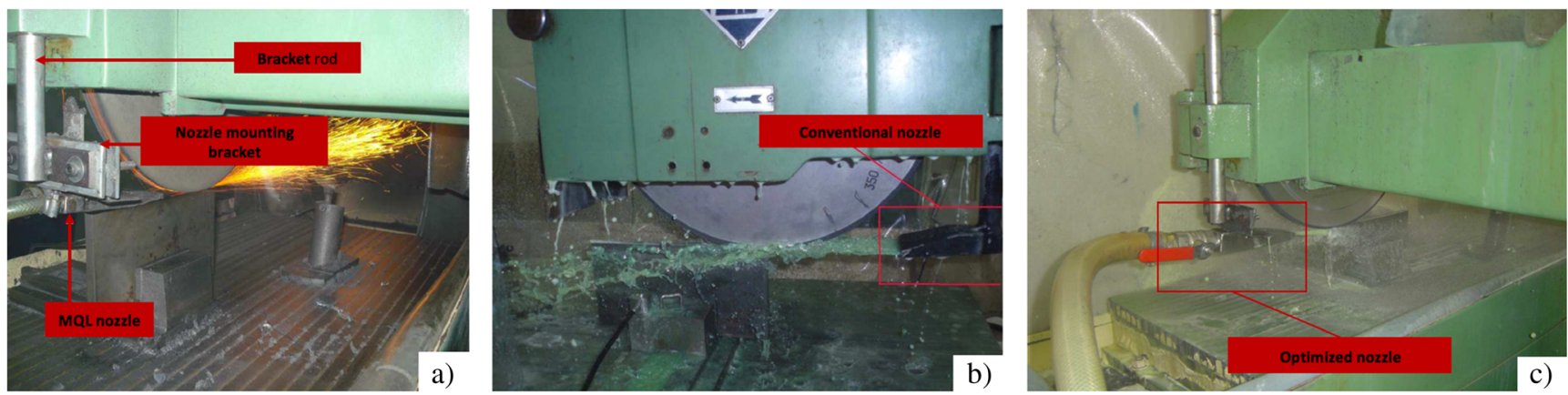

Fig. 2 Experimental setup to perform the grinding tests with the techniques. a MQL. b Conventional. c Optimized

The diametrical wheel wear was measured at the end of each grinding cycle by reproducing its worn wheel surface profile in an AISI 1045 steel (165-232 HB) cylindrical workpiece with the following dimensions: $37 \mathrm{~mm}$ diameter $\times$ $40 \mathrm{~mm}$ length. The cylindrical workpiece was fixed to the grinding table, in such way to remain perpendicular to the grinding wheel's face; then, three measurements at the grinding wheel wear and at the sides regions were performed with the aid of coordinate measuring machine Micro-Hite 3D Direct Computer Control model (DCC), TT10 model, with accuracy of $1 \mu \mathrm{m}$. Finally, the $\mathrm{G}$ ratio was obtained by the division of the material removal volume from the workpiece by the volume of the worn wheel.

Specific regions of workpieces were selected in order to obtain samples with ground surfaces for measurements of microhardness and surface residual stresses, as well as for observation and analysis by scanning electron microscopy (SEM).

After standard metallographic preparation of the workpieces, the Vickers microhardness measurements were performed in a microhardness tester, BUEHLER, model 16006300 using a load of $25 \mathrm{gf}$ provided the best relationship between measures of diagonal, according to the rule establishing a minimum distance of twice the value of the longest imprinted diagonal; in this case, this distance was $20 \mu \mathrm{m}$ since in all imprints, the major diagonal was around $8 \sim 10 \mu \mathrm{m}$. The measurements were replicated five times equidistant from one another and below the machine surface.

As for surface residual stress (i.e., along tangential direction of the ground surface), the X-ray diffraction was applied using a RIGAKU-DEMAX model. The nominal values of residual stress were determined based on the method of multiple exposition (sen2C), following the SAE J784a code. This procedure was detailed by Silva [13].

Scanning electron microscopy (SEM) images were captured at magnification of 2000 times in each sample using a ZEISS scanning electron microscope, DSM 960 model, in which was applied the black-scattered electron technique that allows better analysis of possible damage caused by thermal and mechanical forces on the material's surface.

\section{Results and discussion}

In this session, the results and discussion is presented for the output variables previously mentioned (tangential cutting force, specific energy, surface roughness, abrasive wheel wear, $\mathrm{G}$ ratio, and microhardness of the machined surfaces) after grinding the AISI 4340 steel under various cutting conditions.

\subsection{Cutting force}

Figure 3 shows the cutting forces recorded after machining under various cutting conditions. As expected, cutting forces increased with depth of cut after machining with all the coolant delivery techniques. The higher the depth of cut, the higher the number of abrasive grains in contact with the workpiece, and consequently more intense will be the plastic deformation, thus requiring a higher cutting force.

Also, from the figure can be seen that lower forces were generated at low depth of cut values $(0.02$ to $0.05 \mathrm{~mm})$ after machining with the MQL technique compared to the other
Table 2 Summary of the cooling-lubrication conditions for the experimental trials when grinding the AISI 4340 steel with CBN superabrasive wheel

\begin{tabular}{llll}
\hline Coolant delivery technique & Cutting fluid & Flow rate & Pressure (MPa) \\
\hline MQL & Accu-Lube LB 1000 & Oil-100 ml/h & 0.60 \\
& & Air-4,000,000 ml/h & \\
Conventional & ULTRACUT 370 & $1650,000 \mathrm{ml} / \mathrm{h}$ & 0.40 \\
Optimized & & $(27.5 \mathrm{l} / \mathrm{min})$ & 0.70 \\
\hline
\end{tabular}




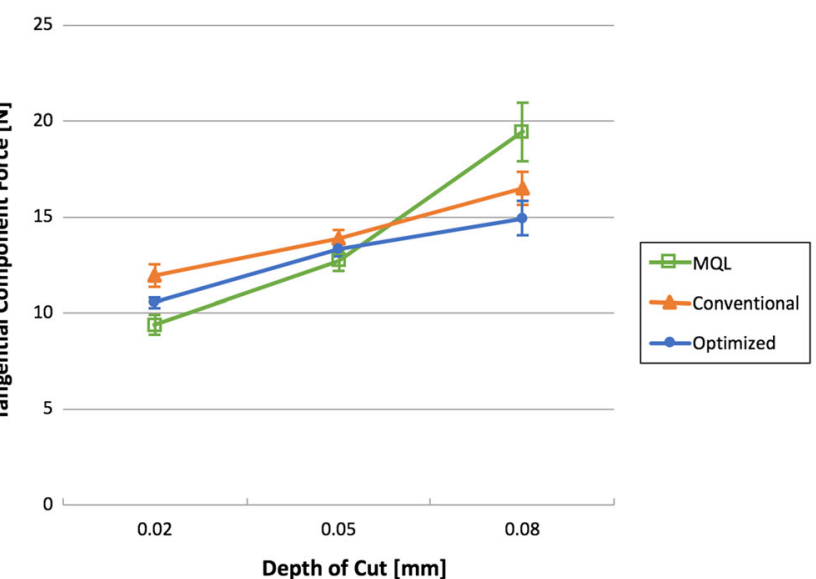

Fig. 3 Tangential component force values versus depth of cut during grinding the AISI 4340 steel under different cooling-lubrication techniques

coolant delivery techniques, indicating that this technique is effective in decreasing friction in the cutting zone due to adequate lubrication provided under less severe conditions, thereby facilitating material removal. However, when machining at depth of cut in excess of $0.05 \mathrm{~mm}$, the MQL was not able to decrease friction between grain and workpiece, generating high cutting efforts. At the same machining conditions, the worst results were obtained after machining with the conventional coolant delivery technique probably due to the wide dispersion of the fluid jet caused by the generous application of cutting fluid in low velocity. The air barrier generated around the abrasive wheel during machining may have obstructed the access of the fluid to the cutting zone, what disturbs the lubricant and coolant fluid action.

In addition, by still comparing the cutting forces results in Fig. 2, it can be seen that machining with the optimized technique posed as an intermediary cooling/lubrication system position, between the flooding and MQL techniques, at less severe conditions (depth of cut up to $0.05 \mathrm{~mm}$ ). However, the optimized technique outperformed the other coolant delivery techniques when under more severe conditions (depth of cut of $0.08 \mathrm{~mm}$ ). Because of the higher pressure in the optimized coolant technique compared to conventional one, the fluid jet penetrates the interface deeply even at machining at higher depth of cut (where cooling function of fluid is required). This action reduces the coefficient of friction between wheel and workpiece [19], as well as lowering the temperature gradient, what can minimize the seizure effect [20]. This probably explains why proportional reduction in cutting force was obtained after grinding with the optimized technique at depth of cut in excess of $0.05 \mathrm{~mm}$.

\subsection{Specific energy}

The specific energy is a measure of machining efficiency (ratio of machining power to material removal rate) and it is composed by the chip removal energy (which effectively cuts the material), the friction between abrasive grains and workpiece, and the energy that causes plastic deformation on the part without material removal [21]. Grinding of most ferrous materials requires high specific energy; thus, it is often referred to a low efficient machining process [22].

According to Mayer [23], the energy input in the system makes the temperature to rise up and, after reaching a critical value, causes a thermal damage in the workpiece surface. In his work after machining a X2M steel, the author showed that is possible to express the thermal damage (like burn) in terms of grinding specific energy. These results show that it is important to keep grinding specific energy levels as low as possible and shall not exceed the critical value to not damage the surface.

From Fig. 4, it can be seen that the specific energy increased with depth of cut values, independent on the coolant delivery technique tested.

Trends observed in specific energy data (Fig. 4) are similar to those observed for the tangential cutting force (Fig. 3). MQL technique again was particularly efficient after machining at depth of cut up to $0.05 \mathrm{~mm}$, while after machining under more severe conditions $(0.08 \mathrm{~mm})$, the MQL technique exhibited the worst performance in terms of removing heat from the grinding zone, compared to other coolant techniques. On the other hand, superior performance was observed after machining with the optimized technique at depth of cut in excess of $0.05 \mathrm{~mm}$ whereas conventional coolant technique in general showed the worst performance under the conditions investigated. The highest specific energy value $\left(39 \mathrm{~J} / \mathrm{mm}^{3}\right)$ was generated after machining with the MQL technique under more severe conditions; however, this value is about $60 \%$ lower than the usually reported value of $100 \mathrm{~J} / \mathrm{mm}^{3}$ when performing fine grinding of hardened steels [22]. Marinescu [22] carried out an investigation to determine specific energy after surface grinding of a SAE 1055 steel with a fine grit CBN grinding wheel (B91ABN200) at different coolant environments (with coolant, synthetic emulsion, and dry condition). Wheel speed of $30 \mathrm{~m} / \mathrm{s}$, workspeed of $0.1 \mathrm{~m} / \mathrm{s}$, and depth

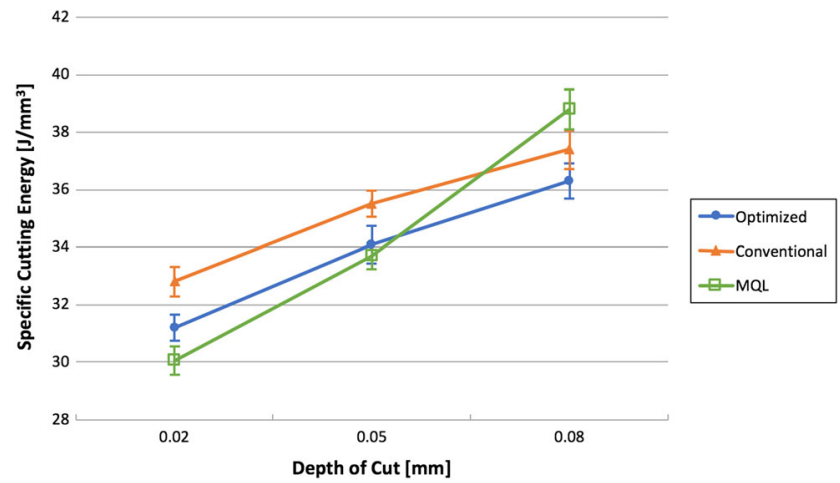

Fig. 4 Specific cutting energy values versus depth of cut after grinding the AISI 4340 steel under different cooling-lubrication techniques 
of cut of $a_{\mathrm{e}}=20 \mu \mathrm{m}$ were kept constant. The specific energy values were 47 and $76 \mathrm{~J} / \mathrm{mm}^{3}$ for wet and dry conditions, respectively. It is clear from these results that the importance of coolant in grinding in order to keep the specific energy in lower levels, thereby preventing thermal damages to the workpiece.

Klocke [24] carried out scratching test in a CK45 N steel grade with diamond as tool to verify the influence of friction on the specific energy in scratching with lubrication (oil and emulsion) and no lubrication condition. The author employed workspeed and cutting speed of 6.25 and of $20 \mathrm{~m} / \mathrm{s}$, respectively, and reported that, for small scratch cross-sections, an improvement in lubrication resulted in higher specific energy that he attributed to the proportionally increased workpiece material deformation. On the other hand, the author observed that for larger scratch cross section, the emulsions and especially the oil provided lower specific energy as a result of the influence of the tangential forces, which dropped with friction.

\subsection{Roughness}

Roughness analysis is important since the surface finish significantly affects workpiece fatigue strength when subjected to forces. This variable is directly related to the lubrication effect and depends mainly on abrasive grain sizes in the grinding wheel, dressing conditions, and material removal rate [21].

As is shown in Fig. 5, roughness values increased with depth of cut as expected, irrespective of the cooling technique employed. Due to increase of the number of active grains per unit area with of depth of cut, grains are more susceptible to fracture or to pull out, thereby increasing the grain spacing, hence theoretical peak-to-valley roughness [22]. Also, the more severe is the plastic deformation during machining, the more are the irregularities on the workpiece surface, thereby resulting in poorer surface finishing.

It can be seen from Fig. 5 that the MQL has higher values than the other two methods. Despite of generating lower tangential cutting force and specific energy at depth of cut values

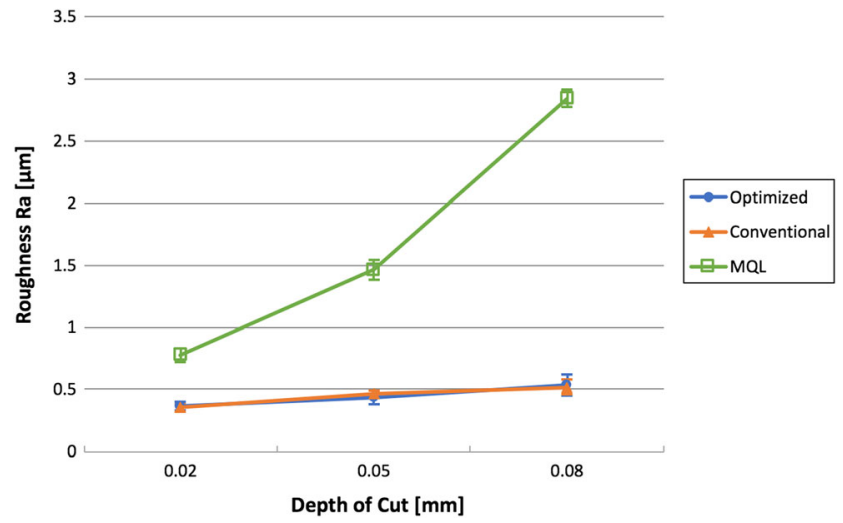

Fig. 5 Roughness values versus depth of cut after grinding under different cooling-lubrication techniques up to $0.05 \mathrm{~mm}$, this technique provided the highest surface roughness values. This indicates that although the MQL method was able to lubricate properly the wheel-workpiece interface for small depths of cut, it was unable to promote appropriate cleaning of the cutting region. According to Malkin and Guo [21], the surface roughness is directly proportional to the workpiece properties as well as grinding conditions, including lubrication and cooling. During the process, there is a formation of a mixture composed of chip, loose grains from grinding wheel, and cutting fluid. This sludge is usually accumulated in the grinding wheel pores and increases as machining progresses probably due to the inefficient cleaning properties of the MQL technique. Therefore, the sludge ends up and adversely affecting the surface quality of the workpiece, as can be observed in Fig. 5. According to Oliveira [25], application of the MQL technique in grinding should have a cleaning system to remove the sludge that accumulate on the wheel's surface, thereby preventing its clogging by dust or grits. When an abrasive wheel face becomes clogged, poor machined surfaces are generated. These authors verified in their work that one successful method for wheel cleaning in MQL grinding is using an air nozzle to clean its surface.

With regard the optimized and conventional coolant techniques, roughness values were very similar and they slightly increased with depth of cut. In general, $R_{\mathrm{a}}$ values were lower than $0.6 \mu \mathrm{m}$ for all the depth of cut values tested, unlike the MQL technique that provided higher surface finish values varying from 0.8 to $2.8 \mu \mathrm{m}$ (at the highest depth of cut). These results confirm the superior performance of the coolant techniques having higher flow rate, which has improved the fluid ability to remove chips out of cutting zone, thereby preventing workpiece surface scratches and damage.

\subsection{Diametrical wear of the wheel and $G$ ratio}

Abrasive wheel wear is mainly caused by three mechanisms: bond fracture, abrasive grain fracture, and abrasive grain friction. This is a very important variable of determining the efficiency of a grinding process, since the higher the abrasive wheel wear, the shorter the life of the wheel, what affects the production cost.

According to Malkin and Guo [21], the increased lubricity effect provided by the cutting fluid reduces grinding wheel wear by decreasing grain-workpiece and chip-bond friction, allowing abrasive grains to stay longer attached to the bond.

Figure 6 shows the diametrical abrasive wear values measured in a CBN wheel after grinding the AISI 4340 steel with different depth of cut values and at various cooling-lubrication techniques. Also, it can be seen from this figure that wear increased with depth of cut, irrespective of the coolant technique employed. Also, the lowest diametrical wear values were obtained after machining with the MQL technique at 


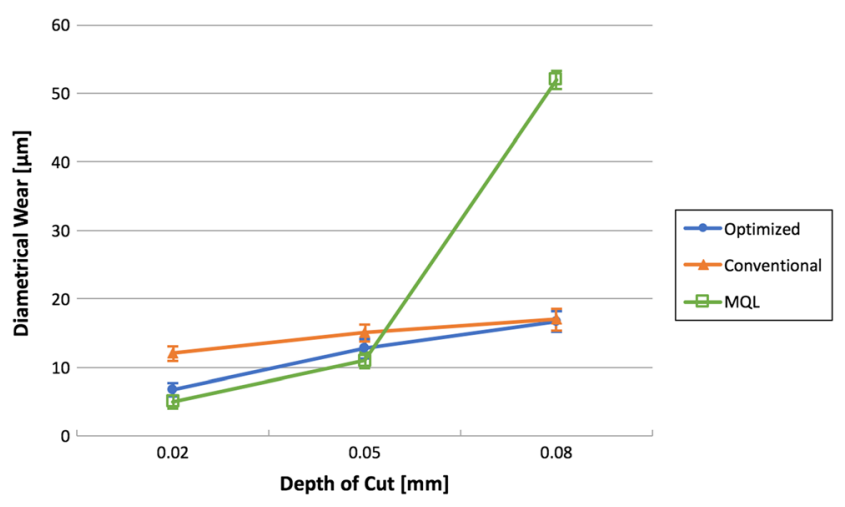

Fig. 6 Wheel diametrical wear versus depth of cut after grinding under different cooling-lubrication techniques

depth of cut values up to $0.05 \mathrm{~mm}(11 \mu \mathrm{m})$; in excess of 0.05 the wear increased abruptly up to $53 \mu \mathrm{m}$.

Once the abrasive wheel employed in this investigation is a CBN type with vitrified bond, this bond is less susceptible to abrasive wear caused by chip friction, providing greater retention force on the abrasive grain and, consequently, reducing diametrical loss. This is one of the reasons why the vitrified bond has been widely accepted in the industry [26].

When machining with the MQL technique at low depth of cut values, chips mixed with the sprayed oil become housed in the pores of the wheel, and consequently make some oil to reach the cutting zone, reducing wear by friction, and removing part of generated heat, improving local cooling. Even if this condition generated a higher surface roughness in the ground workpiece, it was responsible to the reduction in tool wear.

As depth of cut increases, larger chips are generated and then the pores become unable to lodge the chips. When machining with the MQL technique, due to its ineffective cleaning of the cutting zone under the conditions investigated, the chips produced adversely affect the cutting, thus generating a several negative effects, such as higher loads of the tool on the workpiece, reduced lubricity within the cutting zone, damage to the surface of the workpiece, and greater diametrical wear of the grinding wheel.

With regard to the optimized technique, the fact of the fluid being applied at a high velocity (and high pressure) makes it easy to remove the chips when it reaches the cutting zone providing better lubrication and heat removal. Machining with this method provided roughness values similar to the conventional one as well as lower diametrical wear values. This fact might be due to a better chip removal by the fluid jet as compared to the conventional method. Although conventional and optimized methods presented similar performance in terms of roughness, the latter promoted less grinding wheel wear. This fact was also evidenced by low values of tangential force and specific energy.

The $\mathrm{G}$ ratio calculated values after grinding with different depth of cut values and under various cooling-lubrication

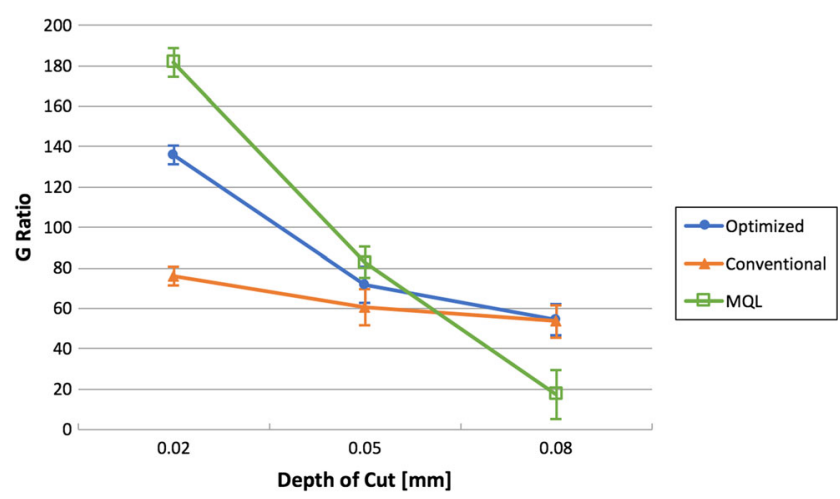

Fig. 7 G ratio comparison among different lubrication/cooling methods

techniques are shown in Fig. 7. MQL has higher $\mathrm{G}$ ratio values indicating high productivity under these conditions (depth of cut of 0.02 and $0.05 \mathrm{~mm}$ ). Under more severe condition (depth of cut of $0.08 \mathrm{~mm}$ ), MQL inefficiency is evident, revealing a high cutting tool wear. Figure 7 synthetizes what has been previously clarified, proving that the cooling-lubrication method affects the cutting forces, the specific energy, roughness, and life of the cutting tool.

\subsection{Microhardness}

Microhardness analysis shows a loss of surface hardness for all applied machining conditions and methods of lubrication and cooling. This hardness fall can be associated with various heating followed by cooling cycles that the ground surface undergoes during the process. Such factors are crucial to define the generated microstructure with lower hardness than the initial ones. In Fig. 8 are showed the microhardness results obtained after grinding with different depth of cut values and under various cooling-lubrication techniques.

According to Malkin and Guo [21], when burning occurs on the surface of hardened steel workpiece, white layer formation, the surface hardness increases due to reaustenitization followed by formation of untempered martensite. By analyzing the results of hardness measurements disposed in the

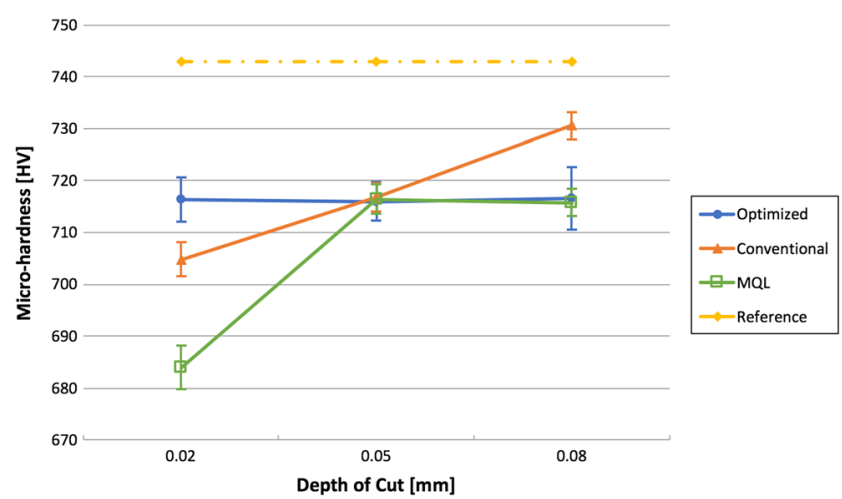

Fig. 8 Micro-hardness values versus depth of cut after grinding under different cooling-lubrication techniques 
Fig. 8, it can be seen that all the microhardness values are lower than those recorded prior to the machining tests (reference value); thus, it can be concluded that no white layer was generated due to burning under the conditions investigated. Also, according to Malkin and Guo [21], when grinding a hardened steel even without any burning, there is generally some softening due to tempering that occurs close to the surface; this statement agrees with Fig. 8, i.e., in all conditions analyzed, there was a decrease in hardness in relation to the initial state of the workpiece, even without occurrence of burning.

According to Callister and Rethwisch [27] the hardness of a quenched and tempered steel depends directly on the temperature and time of tempering process. This dependence was also reported by Malkin and Guo [21]. For the results, values of microhardness loss presented in the most severe cutting condition (depth of cut $=0.08 \mathrm{~mm}$ ) is lower than those recorded after machining under less severe condition (depth of cut of $0.02 \mathrm{~mm}$ ). This can be attributed to the condition with the lowest depth of cut that lasts three times longer than when machining at the most severe one due the constant specific material volume criteria. Thus, though the temperature is lower, the surface is exposed for a longer period of time to the heat generated during chip removal.

When machining at the depth of cut of $0.02 \mathrm{~mm}$, the MQL technique provides the lowest microhardness value of $685 \mathrm{HV}$, compared to the other techniques, thereby suggesting that workpiece experienced severe tempering at this point.

\subsection{Surface residual stresses}

In all the materials subject to external effects, whether mechanical, thermal, chemical, or combination of any one or all the effects induce non-uniform changes in volume of the material, which can be reversible or irreversible, thereby causing the formation of localized stresses therein. For some irreversible changes (localized plastic deformation), they remain in the material caused by the stresses which are referred to as surface residual stresses [28].

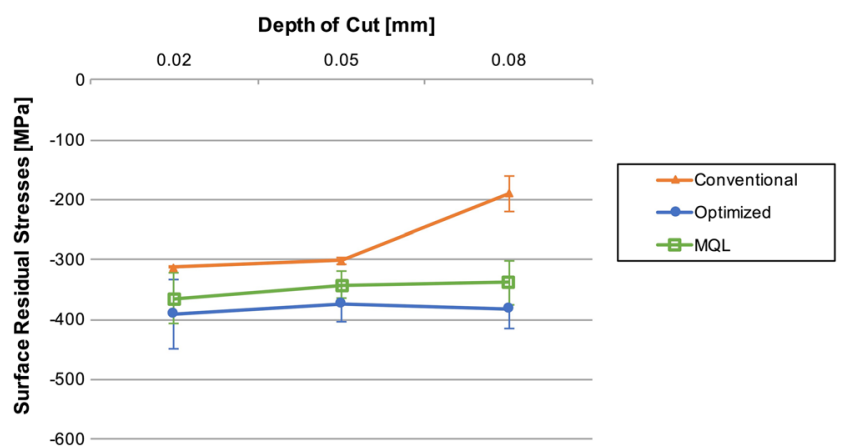

Fig. 9 Surface residual stresses values recorded after grinding with different depth of cut values and under various cooling-lubrication techniques versus depth of cut
Results in Fig. 9 reveal that residual stresses after grinding with different depth of cut values and under various coolinglubrication techniques are relatively medium levels of compressive nature in the induction surface layer. Also, it can be seen that regardless of the depth of cut, only compressive residual stress was induced, irrespective of the coolinglubrication technique employed under the conditions investigated. A slight variation of the residual stresses values with depth of cut after machining with the optimized and the MQL coolant technique, unlike the pattern observed after machining with the conventional coolant delivery technique, in which the highest depth of cut generated the lowest compressive residual stress value. It is well established in the research literature that compressive residual stresses can increase fatigue resistance of a machined component because they reduce service tensile stresses and inhibit crack nucleation, thereby enhancing its endurance performance and consequently increasing its life cycle [29]. The highest compressive stresses were recorded after grinding with optimized coolant technique, representing by about $28 \%$ higher than that recorded for the conventional technique. MQL technique occupied an intermediary position, but with values closer to that obtained after machining with the optimized coolant delivery technique. According to Hamdi [30], the higher the temperature, the higher are the residual stresses; thus, lower compression stresses obtained after grinding with the conventional technique in relation to the optimized can be justified by the greater efficiency of the optimized technique for heat removal. According to Silva [13], the better performance obtained by the MQL technique relative to conventional is mainly because of the lubricity of the fluid used, which reduces the friction coefficient between the wheel and the workpiece.

Kruszynski and Wójcik [31] carried out a study to investigate the residual stress generated after surface plunge grinding of various grades of steels with different hardness (medium carbon steel $28 \mathrm{HRc}$, alloy steel $48 \mathrm{HRc}$, and bearing steel $62 \mathrm{HRc}$ ) under dry and in the presence of cutting fluid. They also tested two different grades of aluminum oxide wheels, grinding depth varying in the range of $0.005-0.06 \mathrm{~mm}$ and workspeed from 0.08 to $0.5 \mathrm{~m} / \mathrm{s}$. Cutting speed was kept constant at a $26 \mathrm{~m} / \mathrm{s}$. These authors proposed a grinding coefficient $\mathrm{B}$, which is a product of power density and wheel/workpiece contact time and residual stress, which can be calculated by measuring the grinding power, workspeed, and depth of cut. According to them, it is an easy to measure "on-line" in a grinding process and strongly correlated with surface integrity parameters, such as residual stresses. They reported that B coefficient decreased as workspeed increased, but it increased with depth of cut in a linear pattern, irrespective of the workpiece material and cooling environment tested. Machining in the presence of coolant provided the lower values of B coefficient. Residual 
stresses reached their maximum (tensile values) close to the surface on depths of 10-20 $\mu \mathrm{m}$. They also observed that the highest slope for B coefficient was obtained after machining the highest hardness material (bearing steel), whereas the lowest one was for alloy steel.

Since tensile residual stress is caused mainly by the combination of thermally induced stresses and deformation associated with the grinding temperature, it can be inferred from results in Fig. 8 that residual stresses are predominantly compressive, thereby confirming that machining conditions employed in this research were appropriated for grinding AISI 4340 steel with CBN wheel. Zhang [32] recently carried out an experimental investigation to evaluate roughness and residual stresses after grinding of crankpin $(40 \mathrm{Cr}$ alloy steel with $52 \pm 3$ of HRC) with CBN wheel (126 grit size) under various cutting conditions and depth of cut varying from 5 to $15 \mu \mathrm{m}$. They reported that high compressive residual stresses remained after path controlled grinding and values increased with cutting speed up to $90 \mathrm{~m} / \mathrm{s}$ but decreased with depth of cut.

\subsection{SEM images of the machined surfaces}

The images of the hardened ASI 1045 steel machined surfaces after grinding with superabrasive $\mathrm{CBN}$ wheel under different cutting conditions are shown in Fig. 10a-i. It can be observed that the feed marks are well defined in all the surfaces and the width of marks generally increased with depth of cut as expected, as the grain contact area increases and hence more material is being deformed. However, evidence of side flow of the workpiece material around the feed marks (indicated by the red arrows) was observed on the machined surfaces after grinding under the more severe condition $\left(a_{\mathrm{e}}=0.080 \mathrm{~mm}\right)$, thereby suggesting the occurrence of severe plastic deformation, especially after machining with the conventional and MQL coolant techniques, Fig. 10c, i, respectively, a fact confirmed by high roughness values measured. Also, by SEM analysis is possible to infer that machining under the MQL technique lead to poor finish, irrespective of the depth of cut employed, despite the high compressive residual stresses and relative lower tangential component forces recorded under

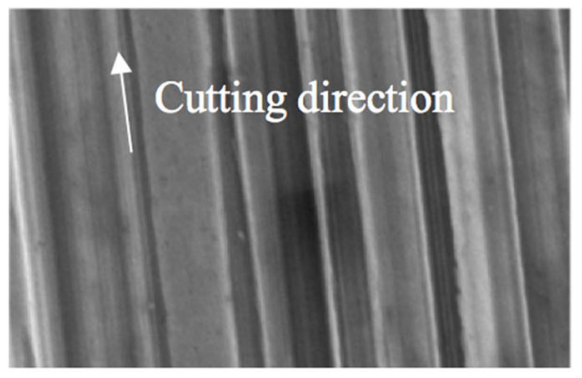

a) Conventional $\left(\mathrm{a}_{\mathrm{e}}=0.02 \mathrm{~mm}\right)$

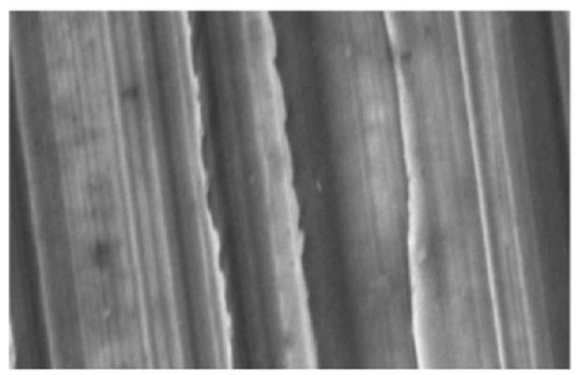

d) Optimized $\left(\mathrm{a}_{\mathrm{e}}=0.02 \mathrm{~mm}\right)$

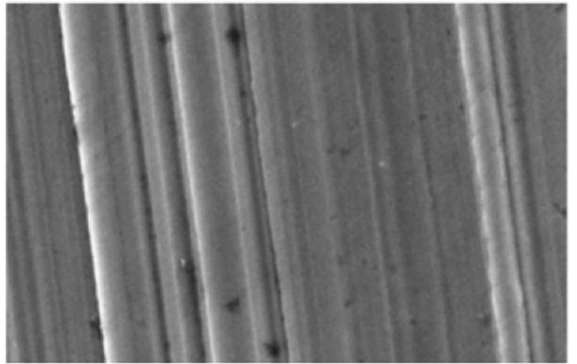

g) MQL $\left(a_{e}=0.02 \mathrm{~mm}\right)$

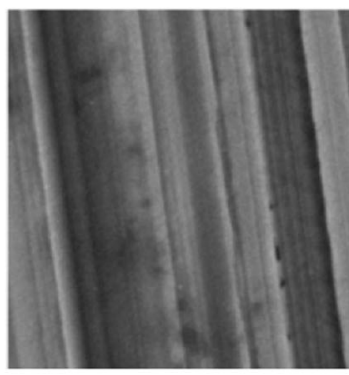

b) Conventional $\left(\mathrm{a}_{\mathrm{e}}=0.05 \mathrm{~mm}\right)$

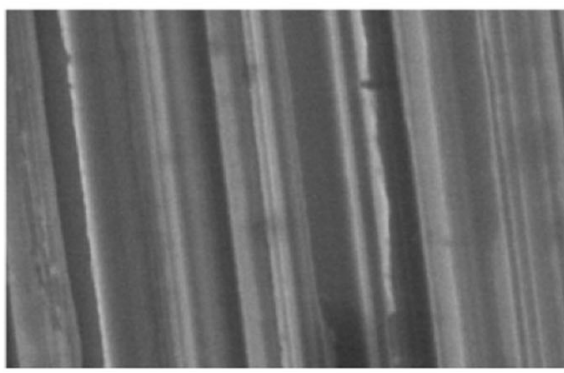

e) Optimized $\left(\mathrm{a}_{\mathrm{e}}=0.05 \mathrm{~mm}\right)$

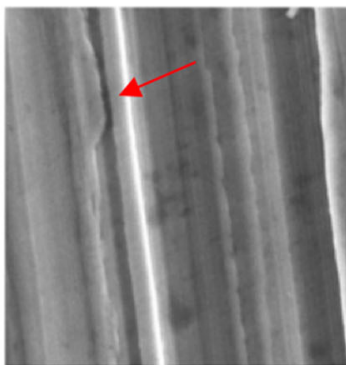

h) MQL $\left(a_{e}=0.05 \mathrm{~mm}\right)$

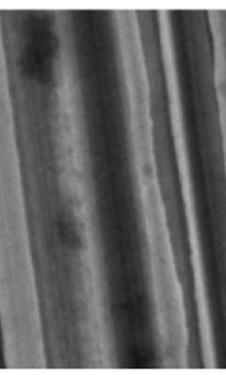

$\overline{\mathrm{x} 2.0 \mathrm{k} 30 \mu \mathrm{m}}$

$\overline{\mathrm{x} 2.0 \mathrm{k} \quad 30 \mu \mathrm{m}}$

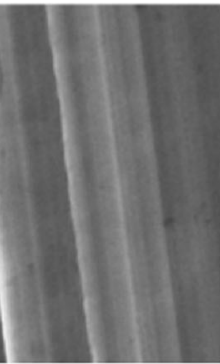

$\overline{\mathrm{x} 2.0 \mathrm{k} \quad 30 \mu \mathrm{m}}$

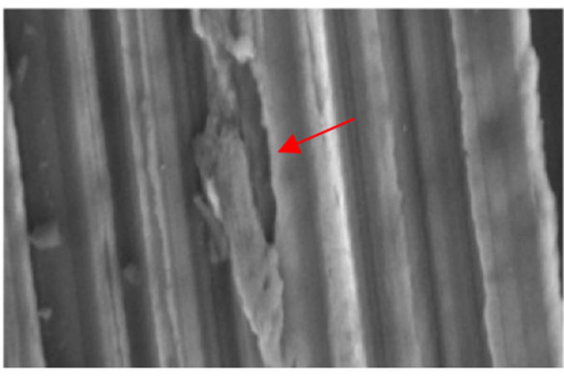

c) Conventional $\left(\mathrm{a}_{\mathrm{e}}=0.08 \mathrm{~mm}\right) \quad \overline{\mathrm{x} 2.0 \mathrm{k} \quad 30 \mu \mathrm{m}}$

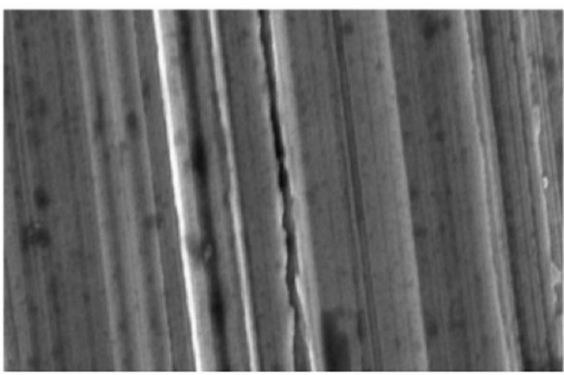

f) Optimized $\left(a_{\mathrm{e}}=0.08 \mathrm{~mm}\right)$

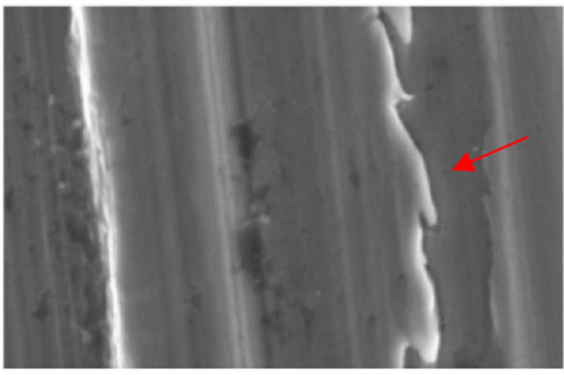

i) MQL $\left(a_{e}=0.08 \mathrm{~mm}\right)$ $\overline{\mathrm{x} 2.0 \mathrm{k} 30 \mu \mathrm{m}}$

Fig. 10 SEM images (magnification of $\times 2000$ ) of the ground surfaces of AISI 4340 steel after machining with CBN wheel under several cutting conditions 
less severe conditions. Also, from Fig. 10 can be observed that there were no significant thermal damages or cracks on the machined surfaces after machining under all the cutting conditions, independent on the cooling-lubrication techniques tested.

\section{Conclusions}

After the analysis of the experimental data of this investigation, the following conclusions can be drawn:

- Tangential component force increased with depth of cut for all the coolant techniques employed. Optimized technique posed as an intermediary cooling/lubrication system position, between the flooding and MQL techniques, after machining under less severe conditions in terms of cutting force. However, the optimized technique outperformed the other coolant delivery techniques when under more severe conditions, i.e., depth of cut of $0.08 \mathrm{~mm}$.

- With regard the specific energy values, the higher results were obtained after machining with the conventional coolant technique. However, different behavior was observed after machining with the MQL technique: superior performance for depth of cut values up to $0.05 \mathrm{~mm}$, unlike for the highest depth of cut $(0.08 \mathrm{~mm})$. The optimized technique proved to be more efficient when machining at more severe conditions.

- Surface roughness increased with depth of cut, irrespective of the coolant technique employed. The lowest $R_{\mathrm{a}}$ values were recorded after machining with the conventional and optimized coolant techniques. MQL technique exhibited the inferior performance with values ranging from 0.8 to $2.8 \mu \mathrm{m}$.

- By observing the machined surfaces, sludge formation that saturates the peripheral surface of the grinding wheel using was observed after machining with the MQL technique, what may requires the use of a cleaning system for the abrasive wheel.

- Similarly to the behavior observed for cutting force, specific energy and surface roughness after machining with the MQL technique, the diametrical wear values were lower at depth of cut values up to $0.05 \mathrm{~mm}$, but they increased abruptly after machining in excess of $0.05 \mathrm{~mm}$.

- The G ratio decreases with increasing depth of cut for all cooling-lubrication techniques tested. The MQL technique presented the better results when machining under less severe conditions, followed by the optimized and conventional technique. However, when machining under more severe conditions (depth of cut $=0.08 \mathrm{~mm}$ ), the MQL gave the worst performance due to the sludge formation at the grinding wheel surface generated during grinding.
- The microhardness results showed that for all coolinglubrication techniques employed and cooling and all for all depths of cut, there were no burns with white layer formation because all the microhardness values found after machining were lower than the initial ones. Hardness decrease pattern was observed when machining with the optimized coolant, irrespective of the depth of cut values, and the best results were recorded when machining under the lowest depth of cut. The greatest decrease in hardness was observed after machining with MQL technique under less severe condition.

- Medium levels of compressive nature residual stresses in the induction surface layer were recorded after grinding, irrespective of the depth of cut and cooling-lubrication techniques tested. Machining under the highest depth of cut generated the lowest compressive residual stress values, whereas the highest compressive stresses were recorded after grinding with optimized coolant technique. This is represented by about $28 \%$ higher than that recorded for the conventional technique. MQL technique occupied an intermediary position, but values closer to that obtained after machining with the optimized coolant delivery technique.

- By the SEM analysis, machining under the MQL technique lead to poor finish, irrespective of the depth of cut employed. Despite the absence of significant thermal damages or cracks on the machined surfaces, evidence of material side flow around the feed marks was observed on the machined surfaces after grinding under more severe conditions with the conventional and MQL coolant techniques.

Acknowledgements This work was supported by the FAPESP (São Paulo Research Foundation) [grant numbers 2007/54514-4 (research assistance), 07/54513-8 (scientific initiation)] and the ITW Chemical Products Ltda-Brazil (donation of the cutting fluid). One of the authors thanks the CAPES for the financial support given by a PNDP projectpost-doctoral scholarship at the FEB-UNESP-BAURU (2016-2017).

\section{References}

1. Sharma VS, Singh G, Sørby K (2014) A review on minimum quantity lubrication for machining processes. Mater Manuf Process 30: 935-953. doi:10.1080/10426914.2014.994759

2. Hryniewicz P, Szeri AZ, Jahanmir S (2000) Coolant flow in surface grinding with non-porous wheels. Int J Mech Sci 42:2347-2367. doi:10.1016/S0020-7403(99)00084-3

3. Irani RA, Bauer RJ, Warkentin A (2005) A review of cutting fluid application in the grinding process. Int J Mach Tools Manuf 45: 1696-1705. doi:10.1016/j.ijmachtools.2005.03.006

4. Ebbrell S, Woolley NH, Tridimas YD et al (2000) The effects of cutting fluid application methods on the grinding process. Int $\mathrm{J}$ Mach Tools Manuf 40:209-223. doi:10.1016/S0890-6955(99) 00060-7 
5. Stanford M, Lister PM (2002) The future role of metalworking fluids in metal cutting operations. Ind Lubr Tribol 54:11-19. doi: $10.1108 / 00368790210415329$

6. Nguyen T, Zhang LC (2003) An assessment of the applicability of cold air and oil mist in surface grinding. J Mater Process Technol 140:224-230. doi:10.1016/S0924-0136(03)00714-3

7. Soković M, Mijanović K (2001) Ecological aspects of the cutting fluids and its influence on quantifiable parameters of the cutting processes. J Mater Process Technol 109:181-189. doi:10.1016/ S0924-0136(00)00794-9

8. Tawakoli T, Hadad MJ, Sadeghi MH et al (2009) An experimental investigation of the effects of workpiece and grinding parameters on minimum quantity lubrication-MQL grinding. Int J Mach Tools Manuf 49:924-932. doi:10.1016/j.ijmachtools.2009.06.015

9. Winter M, Thiede S, Herrmann C (2015) Influence of the cutting fluid on process energy demand and surface roughness in grinding - a technological, environmental and economic examination. Int J Adv Manuf Technol 77:2005-2017. doi:10.1007/s00170014-6557-1

10. Rao PN (2009) Manufacturing technology: metal cutting and machine tools, 2nd edn. McGraw Hill Education, New Delhi

11. Campbell J (1995) Optimised coolant application. In: 1st Int. Mach. Grind. Conf. Society of Manufacturing Engineers, Michigan, pp $12-14$

12. Webster JA, Cui C, Mindek RB, Lindsay R (1995) Grinding fluid application system design. CIRP Ann - Manuf Technol 44:333338. doi:10.1016/S0007-8506(07)62337-3

13. Silva LR, Bianchi EC, Fusse RY et al (2007) Analysis of surface integrity for minimum quantity lubricant-MQL in grinding. Int $\mathrm{J}$ Mach Tools Manuf 47:412-418. doi:10.1016/j.ijmachtools.2006. 03.015

14. Choi HZ, Lee SW, Do JH (2002) The cooling effects of compressed cold air in cylindrical grinding with alumina and CBN wheels. J Mater Process Technol 127:155-158. doi:10.1016/S0924-0136(02) 00117-6

15. Hafenbraedl D, Malkin S (2000) Environmentally-conscious minimum quantity lubrication (MQL) for internal cylindrical grinding. Trans Am Manuf Res Inst SME 149-154

16. Klocke F, Beck T, Eisenblatter G, et al (2000) Applications of minimal quantity lubrication (MQL) in cutting and grinding. In: Proceeding 12th Int. Colloq. Ind. Automot. Lubrif. Technische Akademie, Esslingen, p 11-13

17. Marinescu ID, Hitchiner M, Uhlmann E, et al (2007) Handbook of machining with grinding wheels. CRC Press
18. Belentani RDM, Funes Júnior H, Canarim RC et al (2014) Utilization of minimum quantity lubrication (MQL) with water in CBN grinding of steel. Mater Res 17:88-96. doi:10.1590/S151614392013005000165

19. Lindeke R, Schoeing Jr F, Khan A, Haddad J (1991) Cool your jets. Cut Tool Eng 31-37

20. Mazurkiewicz M, Kubala Z, Chow J (1989) Metal machining with high-pressure water-jet cooling assistance - a new possibility. J Eng Ind 111:7. doi:10.1115/1.3188736

21. Malkin S, Guo C (2008) Grinding technology: theory and application of machining with abrasives, 2nd edn. Industrial Press, New York

22. Marinescu ID, Rowe WB, Dimitrov B, Inasaki I (2004) Tribology of abrasive machining processes, 1st edn. William Andrew, Inc., Norwich

23. Mayer JE Jr, Price AH, Purushothaman GK et al (2002) Specific grinding energy causing thermal damage in helicopter gear steel. J Manuf Process 4:142-147. doi:10.1016/S1526-6125(02)70140-0

24. Klocke F (2009) Manuf Process 2. doi:10.1007/978-3-540-92259-9

25. Oliveira DDJ, Guermandi LG, Bianchi EC et al (2012) Improving minimum quantity lubrication in CBN grinding using compressed air wheel cleaning. J Mater Process Technol 212:2559-2568. doi: 10.1016/j.jmatprotec.2012.05.019

26. Kopac J, Krajnik P (2006) High-performance grinding - a review. J Mater Process Technol 175:278-284. doi:10.1016/j.jmatprotec. 2005.04.010

27. Callister WD, Rethwisch DG (2012) Fundamentals of materials science and engineering: an integrated approach, 4th edition. John Wiley \& Sons

28. Burakowski T, Wierzchon T (1999) Surface engineering of metals: principles, equipment, technologies. CRC Press LLC, Boca Raton

29. Yan X-T, Jiang C, Eynard B (2008) Advanced design and manufacture to gain a competitive edge. doi: 10.1007/978-1-84800-241-8

30. Hamdi H, Zahouani H, Bergheau JM (2004) Residual stresses computation in a grinding process. J Mater Process Technol 147:277285. doi:10.1016/S0924-0136(03)00578-8

31. Kruszyński BW, Wójcik R (2001) Residual stress in grinding. J Mater Process Technol 109:254-257. doi:10.1016/S09240136(00)00807-4

32. Zhang M, Yao Z, Xu S (2015) Optimization of roughness and residual stresses in path controlled grinding of crankpin. Procedia CIRP 36:117-122. doi:10.1016/j.procir.2015.01.056 